\title{
Evaluation of the "safe nesting zone" hypothesis across an urban gradient: a multi-scale study
}

\author{
Jukka Jokimäki, Marja-Liisa Kaisanlahti-Jokimäki, Alberto Sorace, Esteban Fernández-Juricic, Iñaki \\ Rodriguez-Prieto and Maria Dolores Jimenez
} Jokimäki, J., Kaisanlahti-Jokimäki, M.-L., Sorace, A., Fernández-Juricic, E.,
Rodriguez-Prieto, I. and Jimenez, M. D. 2005. Evaluation of the "safe nesting zone"
hypothesis across an urban gradient: a multi-scale study. - Ecography 28: 59-70.

\begin{abstract}
Urban areas have been considered "safe zones" for nesting birds because of low abundance of predators, and consequently low predation pressure. We studied risk of artificial ground nest predation across an urban gradient at regional $(100 \times 100 \mathrm{~km})$ and local scales $(5 \times 5 \mathrm{~km}$, within town) in Finland, Italy, and Spain. Risk of nest predation differed between countries, being greatest in Spain $(66 \%)$, intermediate in Finland $(51 \%)$, and lowest in Italy $(29 \%)$. At the regional scale, risk of nest predation in Finland was lower in small villages and in forest area than in more urbanized sites. In Spain, the risk of nest predation was lower in villages than in the other habitat types. No differences in nest predation risk among habitat types were observed in Italy. At the local level, the risk of nest predation in Finland was higher within the town than in the surrounding forest. In Spain, the risk of nest predation in the surrounding forest area was as high as in the most urbanized areas. No difference in nest predation risk was observed between study plots in Italy at the local level analysis. Our results indicate that nest predation in town centers and their residential areas is similar to or higher than in villages and forest areas refuting the safe nesting zone hypothesis. Risk of nest predation also differed between residential area types within towns. Moreover, the abundance of potential nest predators differed between countries. Magpies and crows were more abundant in Finland than in Italy and Spain, whereas cats, dogs and pedestrians were less abundant in Finland than in the other countries. In Finland, risk of nest predation increased with the abundance of magpies. In Italy and Spain, risk of nest predation increased with the number of pedestrians and in Italy also with the number of cats. In all countries, the risk of nest predation increased with the visibility of the nest. According to our results, urban areas cannot be seen as "safe nesting zones". Actually, changes in nest predation pressure may cause changes in habitat selection patterns and affect bird community structure in urban environments.
\end{abstract}

J.Jokimäki(jukka.jokimaki@ulapland.fi) and M.-L. Kaisanlahti-Jokimäki, Arctic Centre, Univ. of Lapland, P.O. Box 122, FIN-96101 Rovaniemi, Finland. - A. Sorace, Compared Toxicology and Ecotoxicology Lab., National Inst. of Health, Viale Regina Elena 299, Rome, I-00161, Italy. - E. Fernández-Juricic, Dept of Biological Sciences, California State Univ. Long Beach, Peterson Hall 1-109, 1250 Bellflower Blvd., Long Beach, CA 90840, USA. - I. Rodriguez-Prieto, Dept de Ecología Evolutiva, Museo Nacional de Ciencias Naturales, CSIC, José Gutiérrez Abascal 2, E-28006 Madrid, Spain. - M. D. Jimenez, CIFOR-INIA MCYT, Carretera de la Coruña KM 7.5, E28040 Madrid, Spain.

Urbanization is one of the most important large-scale factors negatively affecting the abundance and distribution of many native species and the assemblage of animal communities (Fernández-Juricic and Jokimäki 2001, Marzluff et al. 2001a). Despite the effects of habitat attrition due to urban sprawl, urban environments have

Accepted 23 September 2004 
often been considered "safe zones" with low predation pressure on adult birds because of the low abundance of natural predators, like raptors (Tomiałojc 1982, Kosinski 2001). Indeed, it has been suggested that the low number of predators is the reason why some bird species reach high densities in cities as compared to less urbanized areas (Tomiałojc 1982). Urban environments might be safe zones for many adult birds, but are they "safe nesting zones"? Our knowledge of how urbanization affects the distribution and abundance of nest predators and their ability to find nests remains inadequate.

The putative low predation pressure for adult birds, along with increased availability of food and milder micro-climatic conditions, may also attract, in the longterm, new species to settle in urban areas, even predators (Marzluff 2001). For instance, there is evidence that corvids have increased their numbers in urban habitats throughout the world (Gregory and Marchant 1996, Jokimäki and Huhta 2000; see also Marzluff et al. 2001b and references therein). Therefore, predator-prey interactions may be subject to temporal changes in cities. Moreover, the degree of urbanization may increase the rate of human visitation to natural areas within or close to cities (Fernández-Juricic 2002), which may also increase behavioral and physical disturbance to ground-nesting birds that could lead to lower reproductive success. The combined effects of greater abundance of predators and higher frequency of human-wildlife interactions may call into question the "safe nesting zone" hypothesis (Jokimäki and Huhta 2000, Sorace 2002).

Multiple scales of analysis are often used in habitat selection studies in different habitat types, but generally not in urban environments (Hostetler 2001). However, the use of multiple scales is necessary because, for example, city planners need to know whether the scale at which they manipulate the urban landscape will appreciably reduce or attract species of management interest (namely, predators, pests, etc.). Gradient analysis offers a useful approach to test hypotheses on the impact of urbanization on ecological processes (McDonnel and Picket 1990). Urban development affects the composition and configuration of remnant habitat patches, and exposure to urban disturbance (car traffic, noise, etc.) is considered to change predictably with distance from the urban core (Gilbert 1989). However, the configuration of suitable habitat types within cities may also affect species composition, reproductive success, and mortality (Jokimäki 1999, Fernández-Juricic and Tellería 1999), increasing the complexity of gradient analysis. In this study, we incorporated such spatial complexity by assessing risk of nest predation both at the regional (within countries) and local scales (within towns).

Some authors have reported that risk of nest predation decreases with urbanization, supporting the "safe nesting zone" hypothesis (Gering and Blair 1999). However, others have found high risk of nest predation in urbanized areas (Wilcove 1985, Sasvari et al. 1995, Major et al. 1996, Matthews et al. 1999 and Jokimäki and Huhta 2000). Comparison of studies with different methodological procedures may bolster the controversy about the "safe nesting zone" hypothesis due to geographical differences in landscape attributes and predator assemblages. Moreover, without replicated studies across a variety of locations, the generality of the existing evidence may be questionable.

Predation pressure is expected to change with urbanization because predator communities are different in urban environments relative to natural environments (Tomiałojc 1982). According to the "safe nesting zone" hypothesis, it can be predicted that risk of nest predation and the abundance of nest predators would decrease with urbanization. Moreover, human activity might also affect nesting success by increasing nest losses of ground nesting bird species in areas subject to frequent pedestrian load.

Our objectives were to study the risk of nest predation in relation to the the degree of urbanization (an indirect indicator of human-wildlife interaction rate) and abundance of potential nest predators across urban gradients and multiple spatial scales. We used the same study design and procedures in three European countries to evaluate whether there was geographical variation in the pattern of nest predation. Because nest predation may also be influenced by habitat attributes at the local scale (Huhta et al. 1996, 1998), we also evaluated the role of vegetation structure on the risk of nest predation, and studied if the same factors affected the risk of nest predation in different countries.

\section{Material and methods}

\section{Study sites and scales}

The study was conducted following similar methodological procedures in three European countries: Finland, Italy, and Spain. Three different scales were used: continental scale (between countries comparison), regional scale (within country comparison) and local scale (within town comparison). The continental scale was used to replicate the regional and local scale questions in different landscape contexts. Study plots (each $600 \times$ $500 \mathrm{~m}$ square; i.e. $30 \mathrm{ha}$ ) were established in each country to represent two urban gradients: 1) an urban gradient based on the number of inhabitants at the regional level (hereafter, regional gradient), and 2) an urban gradient based on the local building or construction types at the local level within a town (hereafter, local gradient).

The regional gradient includes six study plots located in: large-sized town (35000-50000 inhabitants, with a radius of $2.7-5.0 \mathrm{~km})$, small-sized town $(10000-$ 18900 inhabitants, with a radius of $0.9-2.5 \mathrm{~km}$ ), large- 
sized village (1000-2500 inhabitants, with radius of 0.5$1.5 \mathrm{~km})$, medium-sized village (600-900 inhabitants, with radius of $0.5-1.3 \mathrm{~km}$ ), small-sized village (333500 inhabitants, with a radius of $0.4-0.6 \mathrm{~km}$ ) and forest area (control area without inhabitants). In addition to this fine-grained gradient, we also present our results by using a coarser gradient: different towns pooled, different villages pooled and forest. According to the standardized terminology of Marzluff et al. 2001a, towns were urban, villages rural and forest wildland areas. The study plots were located within an area of $100 \times 100 \mathrm{~km}$.

The local gradient includes six study plots located in the centre of a large-sized town (ca 35000-50000 inhabitants, with a radius of $2.0-5.0 \mathrm{~km}$; urban area), four types of residential areas within the town (according to Marzluff et al. 2001a suburban areas) and forest surrounding the town (wildland). The four residential area types were: suburban area with block-of-flats, suburban area with both block-of-flats and private houses (hereafter, mixed residential), suburban area with private houses, suburban area with private houses and a large amount (ca $50 \%$ of the size of the study plot) of unmanaged natural parks (e.g. trees and shrubs and a well developed ground/field layer, and no grass cuttings). The study plots were located within town boundaries (within $5 \times 5 \mathrm{~km}$ ). We had no spatial replication in our experimental treatments per se in each country, thus we had, for example, only one large-sized town and privatehouse area per country.

To facilitate comparisons with other studies (see Marzluff et al. 2001a) we characterized each study area. Table 1 shows the location, number of inhabitants, spatial extension and main landscape type of towns and villages. Table 2 describes the percentage cover of different urban landscape elements. In general, the number of inhabitants, the radius of the settlement area, and the proportion of areas with block-of-flats increased with urbanization, whereas the proportion of green areas decreased with urbanization.

\section{Artificial nest predation experiment}

We established 15 artificial ground nests in each study plot. Each nest was located at least $100 \mathrm{~m}$ from each other. A nest was a handmade cup in the soil without any particular constructions. Nests were placed on leaf litter, directly on the ground, under a small tree or shrub, which covered nests directly from above and exposed the nests in the other directions. One egg of Japanese quail Coturnix coturnix was placed in each nest. The nest sites mimicked those of many ground-breeding birds present in our study areas (e.g. Phasanicus colchicus, Galerida cristata, Alauda arvensis, Saxicola torquata, Emberiza cirlus, Emberiza calandra, Emberiza citrinella, Phylloscopus trochilus, Luscinia megarhynchos). No nest markers were used. All the experiments were started during the main laying period of the birds in each study country: 7-9 May 2001 in Italy, 13-19 May 2001 in Spain, and 6-13 June 2001 in Finland. The status of the nest after two weeks of exposure was considered for the analyses. Two weeks is a typical incubation time for many ground-nesting passerines in Europe. A nest was scored as having been preyed upon if the egg had disappeared or been broken. Experimental procedures were similar to Jokimäki and Huhta (2000).

\section{Nest predator surveys and number of people}

Potential avian nest predators (Pica pica, Corvus corone coronelcornix, Corvus monedula, Garrulus glandarius,

Table 1. Basic facts of the study towns and villages.

\begin{tabular}{|c|c|c|c|c|}
\hline & Coordinates & $\begin{array}{c}\text { No. of } \\
\text { inhabitants }\end{array}$ & $\begin{array}{l}\text { Radius of } \\
\text { the town (m) }\end{array}$ & $\begin{array}{c}\text { Main } \\
\text { landscape type }\end{array}$ \\
\hline \multicolumn{5}{|l|}{ Finland } \\
\hline Tapio & $66^{\circ} 42^{\prime} \mathrm{N}, 25^{\circ} 29^{\prime} \mathrm{W}$ & 333 & 500 & Agricultural \\
\hline Sinettä & $66^{\circ} 37^{\prime} \mathrm{N}, 25^{\circ} 28^{\prime} \mathrm{W}$ & 600 & 500 & Agricultural \\
\hline Muurola & $66^{\circ} 22^{\prime} \mathrm{N}, 25^{\circ} 24^{\prime} \mathrm{W}$ & 1100 & 1000 & Forests \\
\hline Kemijärvi & $66^{\circ} 40^{\prime} \mathrm{N}, 27^{\circ} 28^{\prime} \mathrm{W}$ & 12500 & 2500 & Forests \\
\hline Rovaniemi & $66^{\circ} 30^{\prime} \mathrm{N}, 25^{\circ} 45^{\prime} \mathrm{W}$ & 35000 & 5000 & Forests \\
\hline \multicolumn{5}{|l|}{ Italy } \\
\hline La Reggia & $41^{\circ} 40^{\prime} \mathrm{N}, 12^{\circ} 38^{\prime} \mathrm{W}$ & 500 & 400 & Agricultural \\
\hline Casal Lazzara & $41^{\circ} 37^{\prime} \mathrm{N}, 12^{\circ} 35^{\prime} \mathrm{W}$ & 900 & 450 & Agricultural \\
\hline Ardea & $41^{\circ} 36^{\prime} \mathrm{N}, 12^{\circ} 32^{\prime} \mathrm{W}$ & 1800 & 500 & Agricultural \\
\hline Cecchina & $41^{\circ} 41^{\prime} \mathrm{N}, 12^{\circ} 38^{\prime} \mathrm{W}$ & 10000 & 950 & Agricultural \\
\hline Acilia & $41^{\circ} 47^{\prime} \mathrm{N}, 12^{\circ} 22^{\prime} \mathrm{W}$ & 50000 & 2700 & Agricultural \\
\hline \multicolumn{5}{|l|}{ Spain } \\
\hline Navalufuente & $40^{\circ} 49^{\prime} \mathrm{N}, 3^{\circ} 40^{\prime} \mathrm{W}$ & 481 & 560 & Forests \\
\hline Venturada & $40^{\circ} 48^{\prime} \mathrm{N}, 3^{\circ} 37^{\prime} \mathrm{W}$ & 639 & 1250 & Pastures \\
\hline Guadalix de la Sierra & $40^{\circ} 47^{\prime} \mathrm{N}, 3^{\circ} 38^{\prime} \mathrm{W}$ & 2500 & 1500 & Pastures \\
\hline Galapagar & $40^{\circ} 34^{\prime} \mathrm{N}, 4^{\circ} 01^{\prime} \mathrm{W}$ & 18900 & 1500 & Pastures \\
\hline Collado Villalba & $40^{\circ} 38^{\prime} \mathrm{N}, 4^{\circ} 01^{\prime} \mathrm{W}$ & 40000 & 2000 & Pastures \\
\hline
\end{tabular}




\begin{tabular}{|c|c|c|c|c|c|}
\hline & \multicolumn{5}{|c|}{ Cover $(\%)$} \\
\hline & $\begin{array}{l}\text { Housing estates } \\
\text { block-of-flats }\end{array}$ & Single-family & $\begin{array}{l}\text { Parks managed/ } \\
\text { unmanaged }\end{array}$ & Open fields & $\begin{array}{c}\text { Roads and other } \\
\text { paved areas }\end{array}$ \\
\hline \multicolumn{6}{|l|}{ Finland } \\
\hline Large town & 71 & 0 & $7 / 0$ & 0 & 22 \\
\hline Small town & 35 & 15 & $5 / 0$ & 20 & 25 \\
\hline Large village & 20 & 30 & $0 / 15$ & 20 & 15 \\
\hline Average village & 0 & 30 & $0 / 40$ & 10 & 20 \\
\hline Small village & 0 & 5 & $0 / 20$ & 70 & 5 \\
\hline Forest site & 0 & 0 & $0 / 100$ & 0 & 0 \\
\hline \multicolumn{6}{|c|}{ Suburban/residential areas: } \\
\hline $\mathrm{BF}^{(1)}$ & 38 & 0 & $13 / 8$ & 0 & 41 \\
\hline $\mathrm{MA}^{(2)}$ & 28 & 24 & $7 / 17$ & 0 & 24 \\
\hline $\mathrm{SFH}^{(3)}$ & $\begin{array}{r}20 \\
0\end{array}$ & 79 & $0 / 8$ & 0 & 13 \\
\hline $\mathrm{SFHP}^{(4)}$ & 4 & 29 & $0 / 36$ & 0 & 31 \\
\hline \multicolumn{6}{|l|}{ Italy } \\
\hline Large town & 72 & 0 & $11 / 0$ & 2 & 14 \\
\hline Small town & 68 & 1 & $9 / 0$ & 6 & 16 \\
\hline Large village & 51 & 7 & $7 / 0$ & 20 & 16 \\
\hline Average village & 0 & 28 & $19 / 0$ & 43 & 10 \\
\hline Small village & 0 & 25 & $26 / 0$ & 42 & 7 \\
\hline Forest site & 0 & 0 & $0 / 84$ & 9 & 7 \\
\hline \multicolumn{6}{|c|}{ Suburban/residential areas: } \\
\hline $\mathrm{BF}^{(1)}$ & 68 & 0 & $8 / 0$ & 7 & 17 \\
\hline $\mathrm{MA}^{(2)}$ & 47 & 30 & $9 / 0$ & 3 & 12 \\
\hline $\mathrm{SFH}^{(3)}$ & 7 & 58 & $11 / 0$ & 14 & 11 \\
\hline $\mathrm{SFHP}^{(4)}$ & 4 & 39 & $37 / 0$ & 10 & 10 \\
\hline \multicolumn{6}{|l|}{ Spain } \\
\hline Large town & 80 & 5 & $5 / 0$ & 0 & 10 \\
\hline Small town & 70 & 10 & $5 / 5$ & 0 & 10 \\
\hline Large village & 30 & 25 & $5 / 5$ & 10 & 25 \\
\hline Average village & 20 & 30 & $1 / 5$ & 35 & 9 \\
\hline Small village & 15 & 35 & $1 / 14$ & 30 & 5 \\
\hline Forest site & 0 & 0 & $0 / 0$ & 100 & 0 \\
\hline \multicolumn{6}{|c|}{ Suburban/residential areas: } \\
\hline & 75 & 5 & $0 / 0$ & 0 & 10 \\
\hline $\mathrm{MA}^{(2)}$ & 50 & 15 & $20 / 5$ & 0 & 10 \\
\hline $\mathrm{SFH}^{(3)}$ & 5 & 60 & $20 / 5$ & 0 & 10 \\
\hline $\mathrm{SFHP}^{(4)}$ & 5 & 40 & $40 / 15$ & 0 & 5 \\
\hline
\end{tabular}

${ }^{(1)} \mathrm{BF}=$ Area of block-of-flats, ${ }^{(2)} \mathrm{MA}=$ Mixed area of block-of-flats and single-family houses, ${ }^{(3)} \mathrm{SFH}=$ Area of single-family houses, ${ }^{(4)} \mathrm{SFHP}=$ Area of single-family houses and unmanaged parks.

Larus species) were surveyed twice with 5 -min point counts in 15 survey stations in each 30 ha study plot where the artificial ground nest experiments were set up. The first survey was conducted after two weeks and the second survey after three weeks of the establishment of the nests. The highest score of the abundance of each predator species observed during the two visits was used in analyses. All predators seen or heard were recorded between 04:00 and 07:00 during weekdays. Overflying birds that did not land in the study plot were excluded. In each country, surveys were conducted by the same observers.

Number of pedestrians, dogs, cats, red squirrels Sciurus vulgarius, and red foxes Vulpes vulpes were surveyed around each nest during the recording of habitat composition (see below), just after the nest experiment ended. Measurements were conducted in 5-min periods between 04:00 and 07:00 during weekdays.

\section{Habitat descriptions}

The general habitat composition of each of the 30 ha study plots was measured by using maps (scale 1:50001:20 000) and field notes. We estimated the proportion of apartment blocks, single-family houses with gardens, managed parks, unmanaged parks, open fields, and roads and parking areas.

A more detailed description of habitat structure was gathered around each artificial nest immediately after the completion of the nest predation experiment. The vegetation measurements were made using a nest-centered circular plot $\left(3-\mathrm{m}\right.$ radius, area $=28 \mathrm{~m}^{2}$ ). The stem frequency distribution of deciduous and coniferous trees was determined by height classes $(2-5 \mathrm{~m},>5-10 \mathrm{~m}$, and $>10 \mathrm{~m})$. We also measured the total number of shrubs ( $<2 \mathrm{~m}$ of height). We estimated canopy cover of trees $(\%)$ and nest cover above each nest (\%) with a cardboard tube $(10 \mathrm{~cm}$ long $\times 4 \mathrm{~cm}$ in diameter) by looking directly up from height of $1.7 \mathrm{~m}$. Tree canopy 
cover was measured in the four main compass directions from the arc of the 3-m radius vegetation measurement circle; these measurements were then averaged. We estimated the area covered by herbs around the nest site by using $1 \times 1 \mathrm{~m}$ plots centered on the nest, and the maximum height of the ground layer vegetation. To determine the horizontal visibility of each nest, we walked along transects, starting from the nest site, in the four main compass directions, and estimated the distance (in $\mathrm{m}$ ) at which the nest disappeared from the view. The mean value of these four measurements was used as the visibility index for each nest.

\section{Statistical methods}

We first conducted runs-tests to determine whether nests in individual study plots were preyed on independently from one another. A significant result would indicate a departure from a random trend in nest predation. Differences in risk of nest predation between countries and along urbanization gradients within each country were tested with G-tests. Factors affecting risk of nest predation were analyzed with logistic regression analyses, using forward selection procedures ( $p$-value for entry and removal of variables was set to 0.05) and Wald statistics (Anon. 1999). According to Lewis (2004), logistic regression is the most appropriate and flexible statistical test for analyzing factors influencing artificial nest losses. We conducted separate analyses for predator data and for vegetation variables to increase the power of individual tests (see also Wiggins and Møller 1997). The following independent variables were included in the vegetation analysis: tree cover, number of coniferous and broadleaved trees in different height categories, herb cover, height of the ground layer vegetation, number of shrubs, nest cover, and nest visibility. The number of different predator species and pedestrians were included as independent variables in the predator analysis. In the later analyses, only variables significantly affecting risk of nest predation were used in non-parametric KruskallWallis ANOVA and Tukey-type a posteriori tests (Zar 1984) to assess if these variables changed across the two urban gradients within each country. Non-parametric Kruskall-Wallis ANOVA and Tukey-type a posteriori tests were also used to analyze differences in nest predator abundance, number of people and nest visibility between countries.

\section{Results}

\section{Continental scale analysis}

A total of 218 nests $(48.4 \%)$ out of 450 were preyed on during the experiment. Results of the runs-tests were significant $(p<0.05)$ in two out of the 30 study plots, indicating that only in these two plots (Finland, small village, and Spain, forest area) did nest losses deviate from a random sequence of predation.

Risk of nest predation differed between countries $\left(\chi^{2}=43.4, \mathrm{DF}=2, \mathrm{p}<0.001\right)$; being highest in Spain $(66.0 \%, 99$ nests out of 150), intermediate in Finland $(50.7 \%, 76$ out of 150$)$, and lowest in Italy $(28.7 \%, 43$ out of 150). Because risk of nest predation differed among countries, the gradient analyses are presented separately for each country in the next section.

\section{Gradient analysis at the regional level}

In Finland, the risk of nest predation differed between study plots $\left(\chi^{2}=16.1, \mathrm{DF}=5, \mathrm{p}=0.007\right.$, Fig. 1). In general, predation increased with urbanization (Fig. 1). The risk of nest predation was highest in town centers $(60.0 \%, 18$ out of 30$)$, intermediate in villages $(44.4 \%, 20$ out of 45$)$ and lowest in forest area $(13.3 \%, 2$ out of 15$)$

In Italy, the risk of nest predation did not differ between study plots $\left(\chi^{2}=7.5, \mathrm{DF}=5, \mathrm{p}=0.186\right.$, Fig. 1$)$. However, there was a trend towards nest predation risk increasing with urbanization: predation risk was $20.0 \%$ ( 3 out of 15 ) in forest area, $22.2 \%$ in villages ( 8 out of 45 ), and $36.7 \%$ in town centers (11 out of 30 ).

In Spain, the risk of nest predation differed between study plots $\left(\chi^{2}=14.9, \mathrm{DF}=5, \mathrm{p}=0.011\right.$, Fig. 1$)$. Predation was highest in towns $(83.3 \%, 25$ out of 30$)$ and in the surrounding forest area $(86.7 \%, 13$ out of 15$)$ and lowest in villages $(48.9 \%, 22$ out of 45$)$.

\section{Gradient analysis at the local level}

In Finland, the risk of predation differed between study plots $\left(\chi^{2}=15.5, \mathrm{DF}=5, \mathrm{p}=0.008\right.$, Fig. 2$)$. The risk of

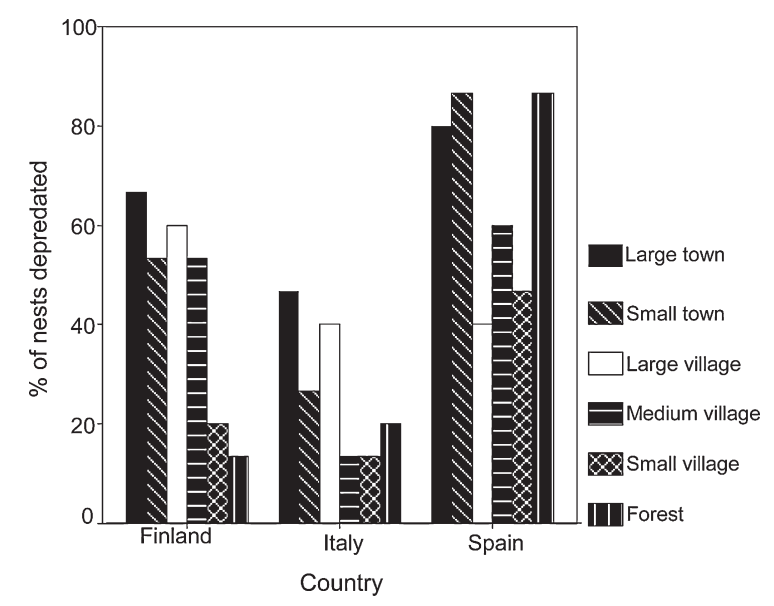

Fig. 1. Risk of nest predation in large-sized town, small-sized town, large-sized village, medium-sized village, small-sized village and forest area in Finland, Italy and Spain. 


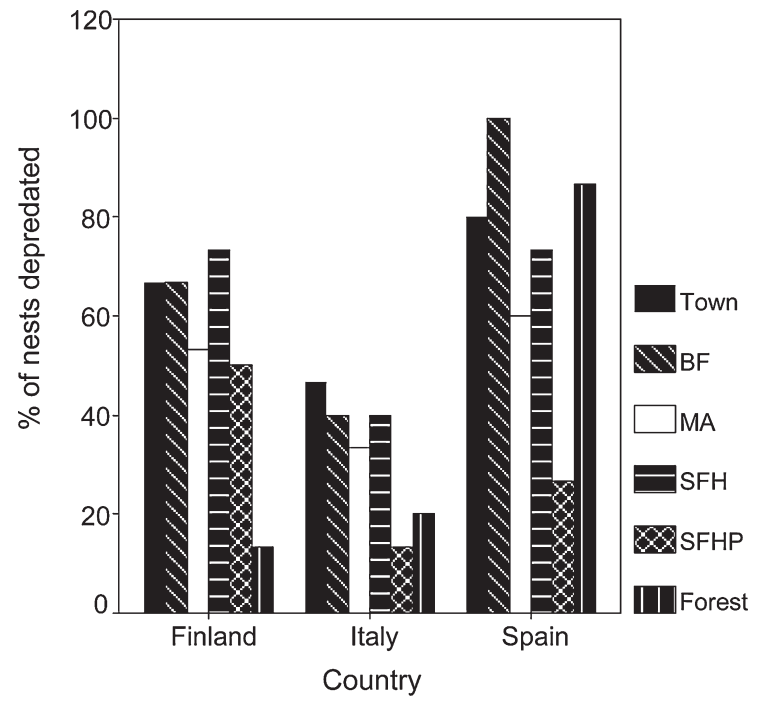

Fig. 2. Risk of nest predation in town center (town), block-of flats area $(\mathrm{BF})$, mixed block-of flats and single-family house area (MA), single-family house area, single-family house area (SFH) with unmanaged parks (SFPH) and surrounding forest area (forest) in Finland, Italy and Spain.

nest predation was higher in the single-family housing area $(73.3 \%, 11$ out of 15$)$, town centre $(66.7 \%, 10$ out of $15)$, and blocks-of-flats area $(66.7 \%, 10$ out of 15$)$. The risk of nest predation in residential areas was $60.0 \%$ (36 out of 60), but did not differ between the four residential area types $\left(\chi^{2}=2.3, \mathrm{DF}=3, \mathrm{p}=0.517\right)$.

In Italy, the number of depredated nests did not differ between study plots $\left(\chi^{2}=6.1, \mathrm{DF}=5, \mathrm{p}=0.293\right.$, Fig. 2$)$. The risk of nest predation in residential areas was $31.7 \%$ (19 out of 60). The risk of nest predation did not differ between the four residential area types $\left(\chi^{2}=3.7, \mathrm{DF}=3\right.$, $\mathrm{p}=0.300)$.

In Spain, the number of depredated nests differed between study plots $\left(\chi^{2}=26.4, \mathrm{DF}=5, \mathrm{p}<0.001\right.$, Fig. 2$)$. The risk of nest predation was higher in block-of-flats area $(100 \%, 15$ out of 15$)$, surrounding forest area $(86.7 \%, 13$ out of 15$)$ and town centre $(80.0 \%, 12$ out of 15), and lower in areas of single-family houses with parks $(26.7 \%, 4$ out of 15$)$. The risk of nest predation in residential areas was $65.0 \%$ (39 out of 60 ). The risk of nest predation differed between residential area types $\left(\chi^{2}=22.7, \mathrm{DF}=3, \mathrm{p}<0.001\right)$, being higher than expected in the block-of-flats area and lower than expected in single-family house area with parks.

\section{Factors affecting the risk of nest predation}

Risk of nest predation, predators, and pedestrians The diversity and abundance of potential nest predators differed greatly among the three countries (Table 3). According to pairwise comparisons, both the abundance of Pica pica and Corvus corone coronelcornix were higher in Finland than in other countries and higher in Spain than in Italy. Corvus monedula and Garrulus glandarius were recorded only in Italy; whereas Larus species were observed only in Finland and foxes only in Italy (Table 3). Red squirrels were more abundant in Finland than in Spain; no squirrels were observed in Italy.

The level of direct (number of pedestrians) and indirect (dogs, cats, etc.) human disturbance surrounding the nests also differed among countries (Table 3). The number of pedestrians was higher in Italy than in other countries and higher in Spain than in Finland. The number of dogs and cats was higher in Italy and Spain than in Finland (Table 3).

In Finland, the risk of nest predation increased with the abundance of Pica pica $(\beta \pm \mathrm{SE}=-0.57 \pm 0.21$, Wald $\chi^{2}=7.5, \mathrm{p}=0.006$ ), but not with the abundance of Corvus corone cornix, the number of pedestrians, dogs or cats. Pairwise comparisions at the regional level indicate that Pica pica was more abundant in the medium-sized villages than in forest or in small-sized villages and Pica pica was also more abundant in largesized villages than in forest and in small-sized villages (Table 4a). At the local level, Pica pica was less abundant in the forest area than in different types of residential areas, and was more abundant in the mixed residential

Table 3. Average number (and SD) of nest predators per survey point in Finland $(n=150)$, Italy $(n=150)$ and Spain $(n=150)$.

\begin{tabular}{|c|c|c|c|c|c|c|c|}
\hline & \multicolumn{2}{|c|}{ Finland } & \multicolumn{2}{|c|}{ Italy } & \multicolumn{2}{|c|}{ Spain } & \multirow{2}{*}{$\begin{array}{l}\text { Kruskall-Wallis } \\
\text { test p-value }\end{array}$} \\
\hline & $\overline{\mathrm{X}}$ & $\mathrm{SD}$ & $\overline{\mathrm{x}}$ & $\mathrm{SD}$ & $\overline{\mathrm{X}}$ & $\mathrm{SD}$ & \\
\hline Pica pica & 1.02 & 0.95 & 0.01 & 0.16 & 0.77 & 0.96 & $<0.001$ \\
\hline Corvus corone coronelcornix & 0.70 & 0.73 & 0.40 & 0.58 & - & - & $<0.001$ \\
\hline Sciurus vulgaris & 0.09 & 0.33 & - & - & 0.01 & 0.08 & $<0.001$ \\
\hline People & 1.38 & 2.53 & 3.15 & 3.71 & 2.36 & 2.97 & $<0.001$ \\
\hline Dogs & 0.05 & 0.22 & 0.23 & 0.51 & 0.21 & 0.44 & $<0.001$ \\
\hline Cats & - & - & 0.21 & 0.58 & 0.14 & 0.37 & $<0.001$ \\
\hline Corvus monedula & - & - & 0.01 & 0.08 & - & - & not tested \\
\hline Garrulus glandarius & - & - & 0.05 & 0.30 & - & - & not tested \\
\hline Larus ridibundus & 0.15 & 0.43 & - & - & - & - & not tested \\
\hline Larus canus & 0.11 & 0.32 & - & - & - & - & not tested \\
\hline Vulpes vulpes & - & - & 0.01 & 0.12 & - & - & not tested \\
\hline
\end{tabular}


Table 4. Mean abundance of predators (individuals/point) affecting risk of nest predation in different countries across regional and local urbanization gradients.

a) regional level

\begin{tabular}{|c|c|c|c|c|c|c|c|c|c|}
\hline & \multicolumn{2}{|c|}{ Towns } & \multicolumn{3}{|c|}{ Villages } & \multirow[t]{2}{*}{ Forest } & \multirow[t]{2}{*}{$\chi^{2}$} & \multirow[t]{2}{*}{$\mathrm{DF}$} & \multirow[t]{2}{*}{$\mathrm{p}$} \\
\hline & large & small & large & med & small & & & & \\
\hline $\begin{array}{l}\text { Finland } \\
\text { Pica pica }\end{array}$ & 0.6 & 0.5 & 1.0 & 1.3 & 0.4 & 0.1 & 22.8 & 5 & $<0.001$ \\
\hline $\begin{array}{l}\text { Italy } \\
\text { Pedestrians } \\
\text { Cats }\end{array}$ & $\begin{array}{l}7.6 \\
0.5\end{array}$ & $\begin{array}{l}4.5 \\
0.1\end{array}$ & $\begin{array}{l}2.7 \\
0.1\end{array}$ & $\begin{array}{l}1.9 \\
0.1\end{array}$ & $\begin{array}{l}1.3 \\
0.2\end{array}$ & $\begin{array}{l}0.3 \\
0.0\end{array}$ & $\begin{array}{r}54.8 \\
4.2\end{array}$ & $\begin{array}{l}5 \\
5\end{array}$ & $\begin{array}{r}<0.001 \\
0.526\end{array}$ \\
\hline $\begin{array}{l}\text { Spain } \\
\text { Pedestrians }\end{array}$ & 3.4 & 4.6 & 0.7 & 0.4 & 0.6 & 0.1 & 63.5 & 5 & $<0.001$ \\
\hline
\end{tabular}

b) local level

\begin{tabular}{|c|c|c|c|c|c|c|c|c|c|}
\hline & \multirow[t]{2}{*}{ Town centre } & \multicolumn{4}{|c|}{ Residential areas } & \multirow[t]{2}{*}{ Forest } & \multirow[t]{2}{*}{$\chi^{2}$} & \multirow[t]{2}{*}{$\mathrm{DF}$} & \multirow[t]{2}{*}{$\mathrm{p}$} \\
\hline & & $\mathrm{BF}^{(1)}$ & $\mathrm{MA}^{(2)}$ & $\mathrm{SFH}^{(3)}$ & SFHP $^{(4)}$ & & & & \\
\hline \multicolumn{10}{|l|}{ Finland } \\
\hline Pica pica & 0.6 & 0.9 & 1.9 & 1.8 & 1.2 & 0.1 & 11.1 & 5 & $<0.001$ \\
\hline \multicolumn{10}{|l|}{ Italy } \\
\hline Pedestrians & 7.6 & 5.9 & 4.0 & 2.4 & 0.9 & 0.3 & 9.4 & 5 & $<0.001$ \\
\hline Cats & 0.5 & 0.3 & 0.3 & 0.3 & 0.1 & 0.0 & 0.9 & 5 & 0.465 \\
\hline \multicolumn{10}{|l|}{ Spain } \\
\hline Pedestrians & 3.4 & 7.6 & 2.3 & 2.9 & 0.9 & 0.1 & 21.4 & 5 & $<0.001$ \\
\hline
\end{tabular}

${ }^{(1)} \mathrm{BF}=$ Area of block-of-flats, ${ }^{(2)} \mathrm{MA}=$ Mixed area of block-of-flats and single-family houses, ${ }^{(3)} \mathrm{SFH}=$ Area of single-family houses,

${ }^{(4)} \mathrm{SFHP}=$ Area of single-family houses and unmanaged parks.

area and in the single-family house area than in the town centre and in the area of block-of-flats (Table 4b).

In Italy, the risk of nest predation increased with the number of cats $\left(\beta \pm \mathrm{SE}=-0.94 \pm 0.35\right.$, Wald $\chi^{2}=7.0$, $\mathrm{p}=0.008)$ and with the number of pedestrians $(\beta \pm \mathrm{SE}=$ $-0.11 \pm 0.05$, Wald $\chi^{2}=4.8, p=0.026$ ), but not with the abundance of Corvus corone cornix, Pica pica, or dogs. At the regional level, number of cats did not differ between study plots, but the number of pedestrians did (Table 4a). According to the pairwise comparisions, the number of pedestrians was higher in large and small towns than in forest and areas of single-family houses. In addition, more people were observed in large town than in mixed residential area. At the local level, the number of cats did not differ between study plots, but the number of pedestrians did (Table 4b). According to the pairwise comparisions, the number of pedestrians was higher in town centre than in other sites, except the area of block-of-flats. In addition, fewer people were observed in the forest area and in the single-family house area with parks than in the area of block-of-flats and in the mixed residential area.

In Spain, the risk of nest predation increased with the number of pedestrians $(\beta \pm \mathrm{SE}=-0.32 \pm 0.11$, Wald $\chi^{2}=8.6, \mathrm{p}=0.003$ ), but not with the abundance of Pica pica, cats, or dogs. At the regional level, the number of pedestrians was higher in towns than in other habitats (Table 4a). According to the pairwise comparisions, the number of pedestrians was higher in large and small towns than in residential areas or in forest. At the local level, the number of pedestrians was higher in the area of block-of-flats, town centre and single-family house area than in the forest area and single-family house area with parks (Tabe 4b). In addition, more people were observed in the area of block-of-flats than in the mixed residential area and in the single-family house area. Also the number of pedestrians was greater in the mixed residential area than in the forest area.

\section{Risk of nest predation and vegetation}

Nest visibility differed among countries $(\mathrm{F}=28.3$, $\mathrm{DF}=2,446, \mathrm{p}<0.001)$, being highest in Spain $(\overline{\mathrm{x}}=$ $3.6 \mathrm{~m}, \mathrm{SD}=2.8, \mathrm{n}=150)$, intermediate in Italy $(\overline{\mathrm{x}}=3.0$ $\mathrm{m}, \mathrm{SD}=1.7, \mathrm{n}=150)$ and lowest in Finland $(\overline{\mathrm{x}}=1.9 \mathrm{~m}$, $\mathrm{SD}=1.2, \mathrm{n}=149$ ). Nest visibility correlated negatively with the total number of shrubs $\left(r_{S}=-0.366\right)$ and the height of the ground layer vegetation $\left(r_{S}=-0.350\right.$; $\mathrm{p}<0.001 ; \mathrm{n}=500$ in both cases).

In Finland, the risk of nest predation increased with the visibility of the nest $(\beta \pm \mathrm{SE}=-0.34 \pm 0.16$, Wald $\left.\chi^{2}=4.5, \mathrm{p}=0.0338\right)$. At the regional level, nest visibility differed between study plots (Table 5a). According to the pairwise comparisons, nest visibility was greater in largeand small-sized towns than in the forest and small- and medium-sized villages (Table 5a). In addition, nest visibility was greater in small-sized town than in largesized village. At the local level, nest visibility differed 
Table 5. Vegetation factors affecting risk of nest predation in different countries across regional and local urbanization gradients.

\begin{tabular}{|c|c|c|c|c|c|c|c|c|c|}
\hline \multicolumn{10}{|c|}{ a) regional level } \\
\hline & \multicolumn{2}{|c|}{ Towns } & \multicolumn{3}{|c|}{ Villages } & \multirow[t]{2}{*}{ Forest } & \multirow[t]{2}{*}{$\chi^{2}$} & \multirow[t]{2}{*}{$\mathrm{DF}$} & \multirow[t]{2}{*}{$\mathrm{p}$} \\
\hline & large & small & large & med & small & & & & \\
\hline \multicolumn{10}{|l|}{ Finland } \\
\hline Visibility of nest & 2.6 & 3.6 & 1.7 & 1.5 & 1.5 & 1.4 & 27.9 & 5 & $<0.001$ \\
\hline \multicolumn{10}{|l|}{ Italy } \\
\hline Visibility of nest & 2.3 & 2.9 & 2.8 & 2.5 & 2.6 & 4.4 & 13.0 & 5 & 0.023 \\
\hline Coniferous trees $5-10 \mathrm{~m}$ & 0.4 & 0.0 & 0.0 & 0.2 & 0.0 & 0.2 & 9.9 & 5 & 0.078 \\
\hline \multicolumn{10}{|l|}{ Spain } \\
\hline Visibility of nest & 6.0 & 5.1 & 1.7 & 1.7 & 0.9 & 3.0 & 48.0 & 5 & $<0.001$ \\
\hline \multicolumn{10}{|c|}{ b) local level } \\
\hline & \multirow[t]{2}{*}{ Town centre } & \multicolumn{4}{|c|}{ Residential areas } & \multirow[t]{2}{*}{ Forest } & \multirow[t]{2}{*}{$\chi^{2}$} & \multirow[t]{2}{*}{$\mathrm{DF}$} & \multirow[t]{2}{*}{$\mathrm{p}$} \\
\hline & & $\mathrm{BF}^{(1)}$ & $\mathrm{MA}^{(2)}$ & $\mathrm{SFH}^{(3)}$ & $\mathrm{SFHP}^{(4)}$ & & & & \\
\hline \multicolumn{10}{|l|}{ Finland } \\
\hline Visibility of nest & 2.6 & 1.6 & 1.7 & 1.6 & 1.6 & 1.4 & 14.2 & 5 & 0.015 \\
\hline \multicolumn{10}{|l|}{ Italy } \\
\hline Visibility of nest & 2.3 & 3.6 & 3.0 & 2.7 & 2.8 & 4.4 & 15.5 & 5 & 0.009 \\
\hline Coniferous trees $5-10 \mathrm{~m}$ & 0.4 & 0.1 & 0.1 & 0.2 & 0.1 & 0.2 & 2.5 & 5 & 0.782 \\
\hline \multicolumn{10}{|l|}{ Spain } \\
\hline Visibility of nest & 6.0 & 7.3 & 3.4 & 4.3 & 2.7 & 3.0 & 28.1 & 5 & $<0.001$ \\
\hline
\end{tabular}

${ }^{(1)} \mathrm{BF}=$ Area of block-of-flats, ${ }^{(2)} \mathrm{MA}=$ Mixed area of block-of-flats and single-family houses, ${ }^{(3)} \mathrm{SFH}=$ Area of single-family houses,

${ }^{(4)} \mathrm{SFHP}=$ Area of single-family houses and unmanaged parks.

between study plots (Table 5b); with higher nest visibility in the town centre than in the other habitats.

In Italy, the risk of nest predation increased with the number of coniferous trees of $5-10 \mathrm{~m}$ height $(\beta \pm \mathrm{SE}=$ $-1.20 \pm 0.49$, Wald $\left.\chi^{2}=6.1, p=0.0134\right)$. In addition, the risk of nest predation increased with increasing visibility of the nest $\left(\beta \pm \mathrm{SE}=-0.30 \pm 0.11\right.$, Wald $\chi^{2}=$ $7.1, \mathrm{p}=0.0077)$. At the regional level, according to the pairwise comparisons, nest visibility was greater in the forest area than in other sites (Table 5a). At the local scale, nest visibility was greater in forest area than in other sites, except for the area of block-of-flats (Table 5b). In addition, nest visibility was greater in area of block-of-flats than in town centre. The number of coniferous trees did not differ between study plots either at regional (Table 5a) or at local scales (Table 5b).

In Spain, the risk of nest predation increased with the visibility of the nest $\left(\beta \pm \mathrm{SE}=-0.48 \pm 0.11\right.$, Wald $\chi^{2}=$ $18.9, \mathrm{p}<0.001)$. At the regional level, according to the pairwise comparisons, nest visibility was higher in largeand small-sized towns and forest than in small- and medium-sized villages (Table 5a). In addition, nest visibility was higher in large-sized town than in largesized village. At the local level, nest visibility was greater in area of block-of-flats and town centre than in foret area, in single-family house area with parks and mixedresidential area (Table 5b). In addition, visibility was greater in single-family house area than in single-family house area with parks.

\section{Discussion}

\section{Risk of nest predation, predators and disturbance in urban environments}

We found that the risk of artificial ground nest predation was higher in (or in some cases similar to) town centers than in other habitats (villages and forests) in the three countries studied. Our study provides the first multiplescale test of nest predation patterns in urbanized environments, suggesting that cities may no longer be predator free areas or areas with low nest predation pressure. Our results agree with previous studies that were conducted at local scales (Wilcove 1985, Sasvari et al. 1995, Major et al. 1996, Matthews et al. 1999, Jokimäki and Huhta 2000, but see Gering and Blair 1999).

Nest predation patterns may be related to the structure of the local predator community. Previous studies have stressed the importance of birds, especially corvids, as nest predators in agricultural, forested, and urban habitats (Andrén et al. 1985, Angelstam 1986, Groom 1993, Jokimäki and Huhta 2000, Haskell et al. 2001). During recent years, magpies and crows have increased their numbers in many countries and expanded their ranges into suburban and urban areas (O'Connor and Shrubb 1986, Birkhead 1991, Gregory and Marchant 1996, Górski 1997, Mancke and Gavin 2000). Earlier studies have found that magpies have an effect on songbird populations (Groom 1993, Major et al. 1996, 
Matthews et al. 1999, Jokimäki and Huhta 2000, but see Gooch et al. 1991). Many corvid species are generalist predators, and are often associated with humanmanaged landscapes like agricultural and urban areas (Andrén 1992, Jokimäki and Huhta 2000). Anthropogenic wastes and feeding may help in maintaining high densities of corvids in urban environments (Väisänen 1994). In addition, many studies have shown the targeting behavior of magpies and crows especially towards ground nests (Parker 1984, Yahner and Wright 1985, Potts 1986). The abundance of nest predators differed among countries. Magpies were abundant in Finnish and Spanish towns, but scarce in Italian towns, whereas crows were not present in our Spanish study plots. The jackdaw Corvus monedula and the Eurasian jay Garrulus glandarius are southerly-distributed species, and they were detected only in Italy. Gulls were observed only in Finnish towns. However, the yellow-legged gull Larus cachinnans is expanding its range in towns in southern Europe (Spanó 1986, Bagnoli and Cignini 1991). Squirrels and foxes are common predator species in many towns (Wilcove 1985, Harris and Rayner 1986, Adkins and Stott 1998). No squirrels were observed in Italy, whereas foxes were only detected in Italy. Rats (Rattus norvegicus and $R$. rattus) are potential nest predators in urban areas (Matthews et al. 1999, Donnelly and Marzluff 2004). Although we have no data on the occurrence of rats, previous evidence suggests that at least in some of our study areas (i.e. Italian urban areas) rats are common (Sorace 2002).

The effects of human activities on nesting success appear controversial. Some authors have noted that human activities might give protection for bird nests located in urban areas (Tomiałojc and Profus 1977, Tomiałojc 1978, Osborne and Osborne 1980, Tarvin and Smith 1995). This putative protective effect may be determined by the frequency, intensity, and predictability of human presence. In our case, risk of nest predation increased with the number of pedestrians in Italy and Spain, but not in Finland where the visitor load was lower than in the other countries. Human induced impacts may be either direct or indirect. Lawn-mowing and trampling might cause great nest losses for ground nesting birds (Jokimäki and Huhta 2000). Gardening may also indirectly reduce nesting success of birds by decreasing the amount of cover and increasing nest visibility. In addition, dogs and cats are mostly associated with human settlements (Wilcove 1985, Kosinski 2001). House cats have reduced the abundance of many bird populations, altered species composition and species distribution (Crooks and Soule 1999), and reduced nesting success of ground-nesting birds in many towns (Gilbert 1989). However, it is not clear if cats really destroy nests at the egg-phase or if cats prey on bird eggs (Haskell et al. 2001). Moreover, dogs may be locally important predators although their impact on ground- nesting birds is presently not well-known (Yanes and Suárez 1996).

\section{Factors affecting the risk of nest predation}

The risk of nest predation differed between countries, being higher in Spain and in Finland than in Italy. The risk of nest predation increased with the abundance of magpie in Finland, with the number of cats in Italy, and with the number of pedestrians in Italy and Spain. It could be that the availability of alternative food sources varied between countries and across urban gradients. Nest predators may switch their food searching towards these alternative sources, resulting in lower rates of predation on bird nests in some of our study areas (see also Doncaster and Maier 1997, Schmidt 1999, Haskell et al. 2001). However, correlation evidence does not mean cause and effect relationships. Luginbuhl et al. (2001) and Marzluff et al. (2001b) have shown similar correlations between crow abundance and nest predation, but crows were very rare nest predators and they were indicative of the presence of many other predator species. We did not identify the predator species responsible to nest losses in our study. However, Jokimäki and Huhta (2000) found in their artificial nest study conducted with plasticine eggs that avian nest predators were responsible for most nest losses in town centers in northern Finland. Unfortunately we have no corresponding data from Italy and Spain.

The main landscape types (forests in Finland, pastoral in Spain and agricultural in Italy) differed between the study countries. Geographical difference in landscape attributes (in our case those related mainly to the visibility of nests, but possibly also to the perching and hiding of predators) can affect patterns of predation along urban gradients. At least partly, the high nest losses in Spain might be explained by the fact that the visibility of nests was greater in Spain than in other study countries. In addition, differences in abundance of most important nest predators may affect the role of different landscape characteristics on nest predation risk (see Andrén 1992, Huhta et al. 1996, Jokimäki and Huhta 2000, Martin and Joron 2003).

In general, nest predation pattern in Spain seems to be rather different than in other countries, the risk of nest predation being exceptionally high in Spanish forest site than in the other countries. However, according to runstests, forest site in Spain showed strong spatial clustering on nest predation suggesting that single predator individual "trap-lined" nests. Therefore, without spatial replicates of Spanish forest site, we can not generalize that the pattern was surely different in Spain than in other countries.

Predation pressure in urban areas might be nest-site dependent. For example, Wilcove (1985) and Sasvári 
et al. (1995) noted that ground nests are more vulnerable to predation than those in foliage or in holes. Moreover, our own artificial nest predation experiments conducted in two Finnish towns (Rovaniemi and Kemijärvi, both areas also included in this study) indicated a lower predation in nests located in nestboxes and within foliage than nests on the ground (Jokimäki and KaisanlahtiJokimäki unpubl.). Avian nest predators are often unable to destroy nests located in holes in trees or buildings, and mammalian predators able to predate nests in holes (e.g. weasel Mustela nivalis and other mustelid's, see Perrins 1979, Sorace et al. 2004) are scarce in urban environments (Gilbert 1989, Amori et al. 1997). Therefore, nest predation might modify urban bird community structure by given selective advantage for hole-nesters over birds nesting on the ground or in the foliage (see also Jokimäki and Huhta 2000).

The risk of nest predation was not the same in all habitat types within town. Urban areas represent heterogeneous landscapes that exhibit considerable variability in predation pressure. Thus, risk of nest predation may also be influenced by habitat structure at finer scales. In all countries, risk of nest predation increased with the visibility of the nest. Our result agrees with Jokimäki and Huhta (2000) who noted that inadequately covered artificial ground nests were more vulnerable to nest predation than well-covered or control nests with normal nest cover. Other vegetation factors than the visibility of the nest were not included in our logistic regression models. Some studies have highlighted that increased vegetation cover, density and height reduce magpie and crow predation (Jones and Hungerford 1972, Sudgen and Beyersbergen 1987, Yahner and Voytko 1989). The missing effect of vegetation factors in the present study can be related to the fact that many vegetation variables were correlated to the visibility of the nest. The concealment of a nest likely affects predation by corvids (and other sight-oriented predators), but not by mammals (and other predators using scent). The increased nest predation in Finland could be due to the fact that corvids were more abundant there.

The possible limitations and potentially misleading inferences made from artificial nest experiments have been recently discussed (Faaborg 2004, Villard and Pärt 2004). The main criticisms to artificial nest experiments are: predation rate might differ between artificial and natural nests (Haskell 1995, Burge et al. 2004), artificial nests might attract a different set of predator species than natural nests with incubating or brooding birds or adults feeding young (Zanette 2002, Thompson III and Burhans 2004), and artificial eggs like quail eggs could be too large for some predators (Haskell 1995). However, use of artificial nests allows standardized sampling procedures and provides reasonable information on the potential risk of nest predation in different habitats (Wilcove 1985). With this technique, we were able to use similar sampling procedures across different landscapes and countries. Jokimäki and Huhta (2000) found that the risk of artificial nest predation in urban environments did not differ among four study years in Finland. Therefore, we believe that our single-year results could give a reliable snapshot of the general risk of nest predation in European urban environments. The use of only eggs may possibly reduce the chance of mammalian predation and the use of ground nests may favor some predators over others (Luginbuhl et al. 2001, Bradley and Marzluff 2003). The results of our study cannot be used to make inferences about overall rates of predation of real nests, but they indicate a consistent trend in an ecological process in urban areas.

\section{Concluding remarks}

Urban areas cannot be considered as "safe nesting zones" with low predation pressure due to absence or low abundance of predators. Predation pressures, both towards nests and adult birds, are increasing in urban areas (Jokimäki and Huhta 2000, Sorace 2002, this study, Fernández-Juricic et al. 2004). Predator species may exhibit increased abundances in urban areas partly due to the reduced human persecution and the greater availability of food. Open ground nesting species may particularly suffer from increased nest predation by avian nest predators and human disturbance in urban environments. This vulnerability might reduce the richness of ground nesting species and overall diversity of urban bird communities.

Acknowledgements - I. Kreivi helped us in collecting field data in Finland. J. Marzluff provided helpful comments on the manuscript. EFJ was supported by the College of Natural Sciences, California State Univ. Long Beach. AS was supported by a post-doctoral fellowship in Ecological Sciences by La Sapienza Univ. of Rome.

\section{References}

Adkins, C. A. and Stott, P. 1998. Home ranges, movements and habitat associations of red foxes Vulpes vulpes in suburban Toronto, Ontario, Canada. - J. Zool. 244: 335-346.

Amori, G. et al. 1997. Il progetto atlante dei mammiferi di Roma. - Ecol. Urbana 9: 9-10.

Andrén, H. 1992. Corvid density and nest predation in relation to forest fragmentation: a landscape perspective. - Ecology 73: 794-804.

Andrén, H. et al. 1985. Differences in predation in relation to habitat fragmentation: an experiment. - Oikos 45: 273-277.

Angelstam, P. 1986. Predation on ground-nesting bird's nests in relation to predator density and habitat edge. - Oikos 47: $365-373$

Anon. 1999. SPSS for Windows. - Release 9.0.1, 24 Feb. 1999.

Bagnoli, R. and Cignini, B. 1991. Nidificazione di Gabbiano reale nella cittá di Roma. - In: Fasola, M. (ed.), Atti II semin. Ital. Censim. Faun. Vertebrati. Suppl. Ric. Biol. Selvaggina 16: $263-265$. 
Birkhead, T. R. 1991. The magpies: the ecology and behaviour of black-billed and yellow-billed magpies. - Poyser.

Bradley, J. E. and Marzluff, J. M. 2003. Rodents as nest predators: influences on predatory behavior and consequences to nesting birds. - Auk 120: 1180-1187.

Burge, D. M. et al. 2004. Patterns of nest predation on artificial and natural nests in forests. - Conserv. Biol. 18: 381-388.

Crooks, K. R. and Soule, M. E. 1999. Mesopredator release and avifaunal extinctions in a fragmented system. - Nature 400: $563-566$.

Doncaster, C. P. and Maier, T. J. 1997. Activity patterns and interactions of red foxes (Vulpes vulpes) in Oxford city. - J. Zool. 241: 73-87.

Donnelly, R. and Marzluff, J. M. 2004. Importance of reserve size and landscape context to urban bird conservation. - Conserv. Biol. 18: 733-745.

Faaborg, J. 2004. Truly artificial nest studies. - Conserv. Biol. 18: $369-370$.

Fernández-Juricic, E. 2002. Can human disturbance promote nestedness? A case study with birds in an urban fragmented landscape. - Oecologia 131: 269-278.

Fernández-Juricic, E. and Tellería, J. L. 1999. Recruitment patterns of blackbirds (Turdus merula) in urban fragmented populations. - Ardeola 46: 61-70.

Fernández-Juricic, E. and Jokimäki, J. 2001. A habitat island approach to conserving birds in urban landscapes: case studies form southern and northern Europe. - Biodiv. Conserv. 10: 2023-2043.

Fernández-Juricic, E. et al. 2004. Effects of opportunistic predation on anti-predator behavioural responses in a guild of ground foragers. - Oecologia 140: 183-190.

Gering, J. and Blair, R. 1999. Predation on artificial bird nests along an urban gradient: predatory risk or relaxation in urban environments? - Ecography 22: 532-541.

Gilbert, O. L. 1989. The ecology of urban habitat. - Chapman and Hall, Cambridge Univ. Press.

Gooch, S., Baillie, S. R. and Birkhead, T. R. 1991. Magpie Pica pica and songbird populations. Retrospective investigation of trends in population density and breeding success. - J. Appl. Ecol. 28: 1068-1086.

Górski, W. 1997. Urban and rural populations of the magpie Pica pica in the Koszalin region, NW Poland. - Acta Ornithol. 32: 51-59.

Gregory, R. D. and Marchant, J. H. 1996. Population trends of jays, magpies and carrion crows in the United Kingdom. - Bird Study 43: 28-37.

Groom, D. W. 1993. Magpie Pica pica predation on blackbird Turdus merula nests in urban areas. - Bird Study 40: 55-62.

Harris, S. and Rayner, J. M. V. 1986. Urban foxes (Vulpes vulpes) population estimates and habitat requirements in several British cities. - J. Anim. Ecol. 55: 575-591.

Haskell, D. G. 1995. Forest fragmentation and nest predation: are experiments with Japanese quail eggs misleading? - Auk 112: $767-770$.

Haskell, D. G., Knupp, A. M. and Schneider, M. C. 2001. Nest predator abundance and urbanization. - In: Marzluff, J. M., Bowman, R. and Donnelly, R. (eds), Avian ecology and conservation in an urbanizing world. Kluwer, pp. 243-258.

Hostetler, M. 2001. The importance of multi-scale analyses in avian habitat selection studies in urban environments. - In: Marzluff, J. M., Bowman, R. and Donnelly, R. (eds), Avian ecology and conservation in an urbanizing world. Kluwer, pp. $139-154$.

Huhta, E., Mappes, T. and Jokimäki, J. 1996. Predation on artificial ground nests in relation to forest fragmentation, agricultural land and habitat structure. - Ecography 19: $85-91$

Huhta, E., Jokimäki, J. and Helle, P. 1998. Predation on artificial nests in forest dominated landscape - the effects of nest type, patch size and edge structure. - Ecography 21: 464-471.
Jokimäki, J. 1999. Occurrence of breeding bird species in urban parks: effects of park structure and broad-scale variables. - Urban Ecosyst. 3: 21-34.

Jokimäki, J. and Huhta, E. 2000. Artificial nest predation and abundance of birds along an urban gradient. - Condor 102: $838-847$.

Jones, R. E. and Hungerford, K. E. 1972. Evaluation of nesting cover as protection from magpie predation. - Wildl. Manage. 36: 727-732.

Kosinski, Z. 2001. Effects of urbanization on nest site selection and nesting success of the greenfinch Carduelis chloris in Krotoszyn, Poland. - Ornis Fenn. 78: 175-183.

Lewis, K. P. 2004. How important is the statistical approach for analysing categorical data? A critique using artificial nests. - Oikos 104: 305-315.

Luginbuhl, J. H. et al. 2001. Corvid survey techniques and the relationship between corvid relative abundance and nest predation. - J. Field Ornithol. 72: 556-572.

Major, R. E., Gowing, G. and Kendal, E. 1996. Nest predation in Australian urban environments and the role of the pied currawong Strepera graculina. - Aust. J. Ecol. 21: 399-409.

Mancke, R. G. and Gavin, T. A. 2000. Breeding bird density in woodlots: effects of depth and building at the edges. - Ecol. Appl. 10: 598-611.

Martin, J.-L. and Joron, M. 2003. Nest predation in forest birds: influence of predator type and predator's habitat quality. - Oikos 102: 641-653.

Marzluff, J. M. 2001. Worldwide urbanization and its effects on birds. - In: Marzluff, J. M., Bowman, R. and Donnelly, R. (eds), Avian ecology and conservation in an urbanizing world. Kluwer, pp. 19-48.

Marzluff, J. M., Bowman, R. and Donnelly, R. 2001a. A historical perspective on urban bird research: trends, terms, and approaches. - In: Marzluff, J. M., Bowman, R. and Donnelly, R. (eds), Avian ecology and conservation in an urbanizing world. Kluwer, pp. 1-18.

Marzluff, J. M. et al. 2001b. Causes and consequences of expanding American crow populations. - In: Marzluff, J. M., Bowman, R. and Donnelly, R. (eds), Avian ecology and conservation in an urbanizing world. Kluwer, pp. 331-363.

Matthews, A., Dickmand, C. R. and Major, R. E. 1999. The influence of fragment size and edge on nest predation in urban bushland. - Ecography 22: 349-356.

McDonnel, M. J. and Picket, S. T. A. 1990. Ecosystem structure and function along urban-rural gradients: an unexploited oppurtunity for ecology. - Ecology 71: 1232-1237.

O'Connor, R. J. and Shrubb, M. 1986. Farming and birds. - Cambridge Univ. Press.

Osborne, P. and Osborne, L. 1980. The contribution of nest site characteristics to breeding-success among blackbirds Turdus merula. - Ibis 122: 512-517.

Parker, H. 1984. Effects of corvid removal on reproduction of willow ptarmigan and black grouse. - J. Wildl. Manage. 48: 1197-1205.

Perrins, L. 1979. British tits. - Collins.

Potts, G. R. 1986. The partridge. Pesticides, predation and conservation. - Collins.

Sasvari, L., Csörgõ, T. and Hahn, I. 1995. Bird nest predation and breeding density in primordial and man-made habitats. - Folia Zool. 44: 305-314.

Schmidt, K. A. 1999. Foraging theory as a conceptual framework for studying nest predation. - Oikos 85: 151-160.

Sorace, A. 2002. High density of bird and pest species in urban habitats and the role of predator abundance. - Ornis Fenn. 79: $60-71$.

Sorace, A., Petrassi, F. and Consiglio, C. 2004. Long-distance relocation of nestboxes reduces nest predation by pine marten Martes martes. - Bird Study 51: 119-124.

Spanó, S. 1986. Nidificazione di Gabbino reale, Larus cachinnans, nella cittá di Genova. - Riv. Ital. Ornithol. 56: 269-270. 
Sudgen, L. G. and Beyersbergen, G. W. 1987. Effect of nesting cover density on American crow predation of simulated duck nests. - J. Wildl. Manage. 51: 481-485.

Tarvin, K. A. and Smith, K. G. 1995. Microhabitat factors influencing predation and success of suburban blue jay Cyanocitta cristata nests. - J. Avian Biol. 26: 296-304.

Thompson, III, F. R. and Burhans, D. E. 2004. Differences in predators of artificial and real songbirds nests: evidence of bias in artifical nest studies. - Conserv. Biol. 18: 373-380.

Tomiałojc, L. 1978. The influence of predators on breeding woodpigeons in London parks. - Bird Study 25: 2-10.

Tomiałojc, L. 1982. Synurbanization of birds and prey-predators relations. - In: Luniak, M. and Pisarski, B. (eds), Animals in urban environments. Ossolineum, pp. 131-137.

Tomiałojc, L. and Profus, P. 1977. Comparative analysis of breeding bird communities in two parks of Wroclaw and in an adjancend Querco-Carpinetum forest. - Acta Ornithol. 16: $117-177$.

Yahner, R. H. and Wright, A. L. 1985. Depredation on artificial ground nests: effects of edge and plot age. - J. Wildl. Manage. 49: 508-513.
Yahner, R. H. and Voytko, R. A. 1989. Effects of nest-site selection on depredation of artificial nests. - J. Wildl. Manage. 53: 21-25.

Yanes, M. and Suárez, F. 1996. Incidental nest predation and Lark conservation in an Iberian semiarid shrubsteppe. - Conserv. Biol. 10: 881-887.

Väisänen, R. A. 1994. Talvilinnusto $1993 / 94$ ja runsaimmat lajit 19 viime talvena (Winter birds in Finland in 1993/94 and the most abundant species in the censuses of last 19 years). - Linnut 29: 20-26, in finnish with English summary.

Villard, M.-A. and Pärt, T. 2004. Don't put all your eggs in real nests: a sequel to Faaborg. - Conserv. Biol. 18: 371-372.

Wiggins, D. A. and Møller, A. P. 1997. Island size, isolation, or interspecific competition? The breeding distribution of the Parus guild in the Dannish archipelago. - Oecologia 111: 255-260.

Wilcove, D. S. 1985. Nest predation in forest tracts and the decline of migratory songbirds. - Ecology 66: 1211-1214.

Zanette, L. 2002. What do artifical nests tell us about nest predation? - Biol. Conserv. 103: 323-329.

Zar, J. H. 1984. Biostatistical analysis. - Prentice-Hall. 